\title{
A STUDY OF EMISSION REDUCTION BY USING ALCOHOL BLEND FUEL FOR SMALL DIESEL ENGINE
}

\author{
Tadashige Kawakami \\ Faculty of Science and Engineering Hosei University \\ Kajino-cho, Koganei, Tokyo 184-8584 Japan \\ Kawakami@hosei.ac.jp
}

\begin{abstract}
In practical diesel engines it is to achieve a low emission and low fuel consumption under from low to high load operation conditions. Several techniques were developed for the low emission and high efficiency, such as Homogeneous Charge Compression-Ignition Engines and the blend fuels. Nevertheless, there are only few data available for reducing the emissions and fuel consumption of small diesel engines by using blend fuels. This experiment has been carried out to examine the influence of alcohol blend fuels on combustion characteristics for small diesel engine. The fuels used in this study are light oil (Standard), ethanol, propanol and butanol. The combustion behaviours, such as the emissions in exhaust gas ( $\mathrm{NO}_{4}, \mathrm{CO}, \mathrm{CO}_{2}, \mathrm{O}_{2}$ concentration), fuel consumption rate are observed. The main conclusions are as follows:

1) it is possible to control the combustion behaviour by using alcohol blend fuels for small diesel engine,

2) the fuel consumption of at any alcohol blend fuels is bigger than that of light oil,

3) the net thermal efficiency of some alcohol blend fuels (E5P5, P5B5, E5B5) slightly increases than that of light oil,

4) the NOx emissions for all the alcohol blend fuels are smaller than that of light oil,

5) the CO emissions are remarkably bigger than that of light oil under from low to middle engine load without the ethanol $10 \%$ addition.
\end{abstract}

Keywords: low emission, small diesel engine, alcohol blend fuel

\section{Introduction}

Nowadays, the global environmental problems and the global energy problems become very serious. Internal combustion engines are main causes of these problems. So it is necessary to achieve low emissions and low fuel consumption for internal combustion engines. Especially, in automotive diesel engines, low-particulate and low- $\mathrm{NO}_{\mathrm{X}}$ emissions are very much needed by using blend fuels and emulsified hydrocarbon fuels. For example, several techniques were developed for reduction of $\mathrm{NO}_{\mathrm{x}}, \mathrm{CO}, \mathrm{HC}$ emissions from the diesel engines such as EGR (Exhaust gas recirculation), lean combustion and Homogeneous Charge Compression Ignition (HCCI) [1-8].

As the first step in this study, experiments have been carried out to determine the influence on combustion characteristics and exhaust emissions for small diesel engines by using alcohol blend fuels. The combustion behaviours, such as the emissions in exhaust gas $\left(\mathrm{NO}_{\mathrm{X}}, \mathrm{CO}, \mathrm{CO}_{2}, \mathrm{O}_{2}\right.$ concentration), fuel consumption rate are observed. The fuels used in this study are light oil, alcohol blend fuels (ethanol, propanol and butanol). Mixing rate is varied by the changing volume of alcohol in the blend fuels. The emissions in exhaust gas are measured with an analyser of exhaust gas. The data of 30 tests for each engine revolutions were averaged arithmetically.

\section{Experimental Apparatus and Procedure}

Figure 1 shows the experimental set up employed in this study. It consists of a small diesel engine (Yanmar Co. TF70V-E: $382 \mathrm{cc}$ 4-stroke) and an analyser of exhaust gas (AVL Di COM 4000: NOx: Chemiluminesence, $\mathrm{CO}$ and $\mathrm{CO}_{2}$ : NDIR, $\mathrm{O}_{2}$ : Zirconia). Tab. 1 shows the engine specifications of the diesel engine in this study. The fuels used in this study are light oil (Standard), ethanol, propanol and butanol. 


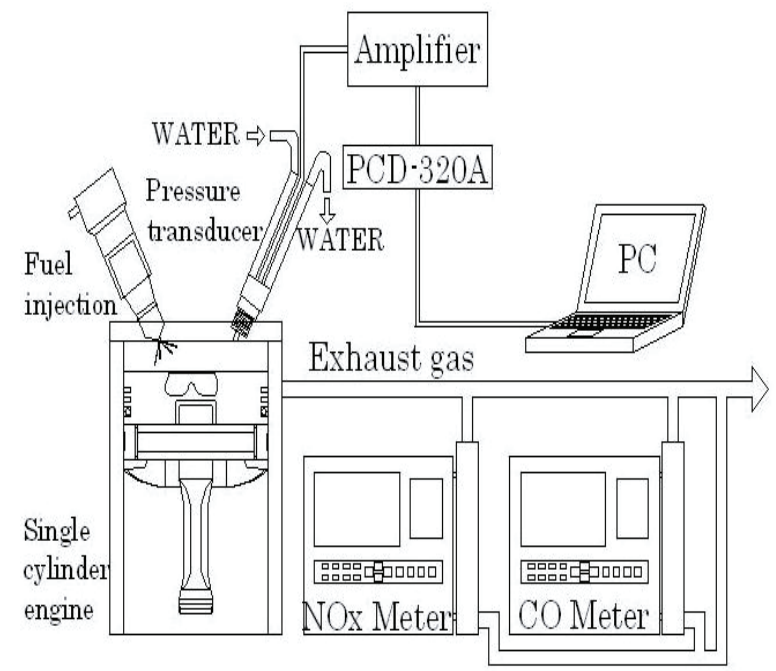

Fig. 1. Experimental device

Tab. 1. Engine specifications

\begin{tabular}{|c|c|}
\hline Engine type & 4-stroke diesel engine \\
\hline Combustion system & Direct injection \\
\hline Cooling system & Water-cooling system \\
\hline Number of cylinder & 1 \\
\hline Bore*Stroke & $78 \mathrm{~mm} 80 \mathrm{~mm}$ \\
\hline Displacement & $382 \mathrm{cc}$ \\
\hline Valve system & OHV \\
\hline Injection pressure & $11.8 \mathrm{MPa}$ \\
\hline Compression ratio & 21.4 \\
\hline Maximum output & $5.5 \mathrm{~kW} / 2600 \mathrm{rpm}$ \\
\hline
\end{tabular}

\section{Results and Discussion}

Figure 2 shows the fuel consumption rate against the engine load as a function of ethanol blend rate. Where, for example, Ethanol 10\%: 90 vol\% light oil+10 vol\% ethanol.

As can be seen from this figure, the fuel consumption rate increases with increasing the rate of addition of ethanol, from low to middle engine load conditions, $(25 \%, 50 \%)$. Furthermore, under high engine load conditions the fuel consumption is almost constant at any rate of addition of ethanol. This fact may be due to the influence of oxygen in ethanol under high load conditions.

Figure 3 shows the fuel consumption rate against the engine load as a function of alcohol blend rate. In this study, the fuel consumption rate is calculated from the value of the fuel consumption divided by the brake output. Five alcohol blend fuels were used:

where:

- E2.5B2.5: Ethanol 2.5 vol\%, Butanol 2.5 vol $\%$ and light oil 95 vol\%,

- P5B5: Propanol 5 vol\%, Butanol 5 vol\% and light oil 90 vol $\%$,

- E5P5: Ethanol 5 vol\%, Propanol 5 vol\% and light oil 90 vol\%,

- E10B10: Ethanol 10 vol\%, Butanol 10 vol\% and light oil 80 vol\%,

- E10P10: Ethanol 10 vol\%, Propanol 10 vol\% and light oil 80 vol\%,

- P10B10: Propanol 10 vol percentage, Butanol 10 vol\% and light oil 80 vol\%.

From this figure, it can be seen that the fuel consumption rate is not so difference under middle and high engine load conditions $(50 \%, 75 \%, 100 \%$ and $110 \%)$. This fact indicated that over the middle engine load conditions the normal combustion behaviour is realized for small diesel engine by using alcohol blend fuel. On the other hand, the fuel consumption of at any alcohol blend fuels is bigger than that of light oil. This fact can be readily explained the effect of the calorific value for alcohol blend fuels. 


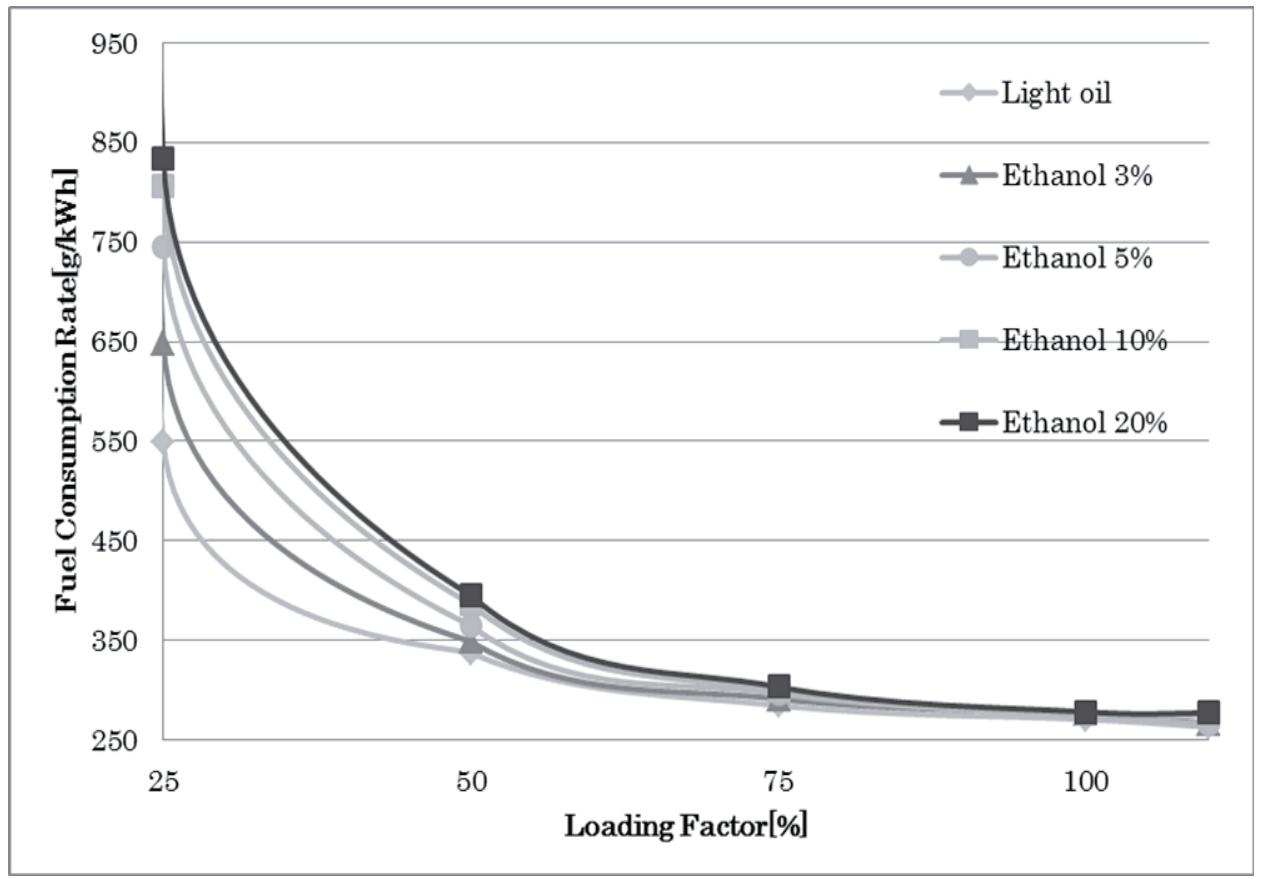

Fig. 2. Fuel Consumption Rate (Ethanol+light oil)

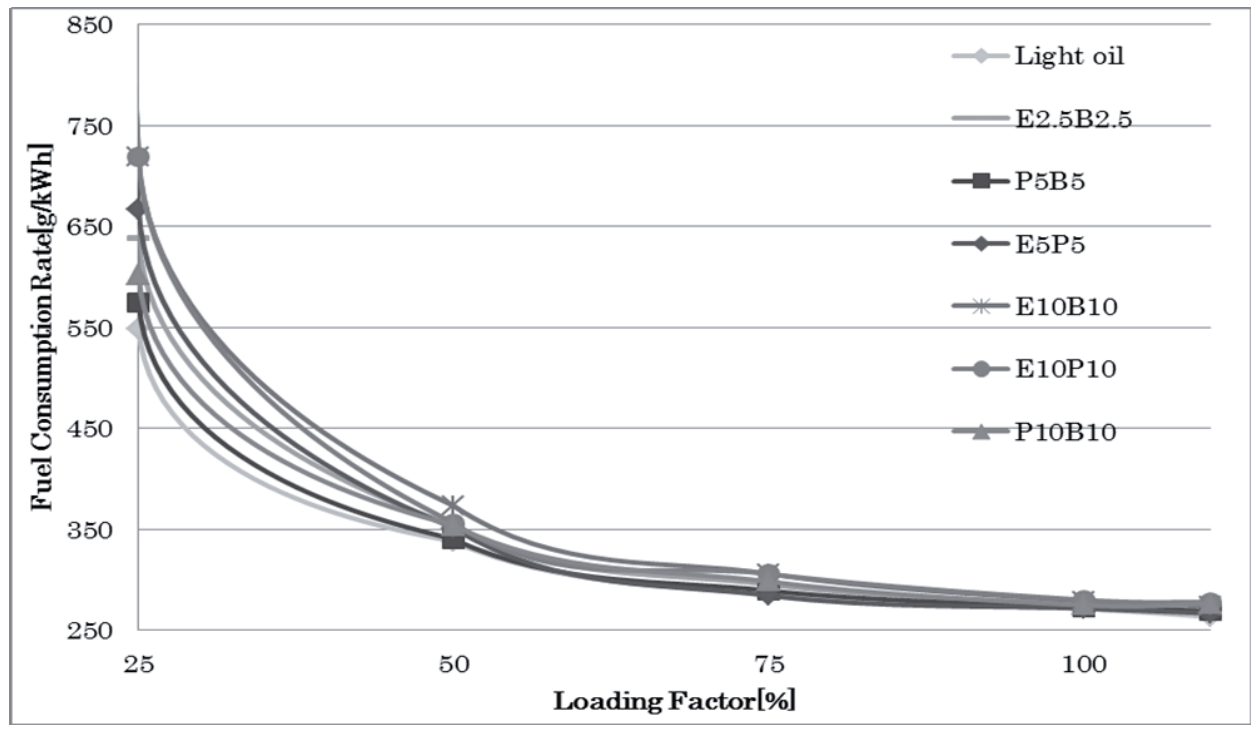

Fig. 3. Fuel Consumption Rate (Alcohol blend fuel)

Figure 4 shows the net thermal efficiency against the engine load as a function of blend fuel type. The net thermal efficiency is calculated from the brake output divided by the calculated value of heat supply. From this figure, it can be seen that, the net thermal efficiency is almost constant at same engine load under middle and high load conditions $(50 \%, 75 \%, 100 \%$ and $110 \%)$. Furthermore, it is interesting facts that the net thermal efficiency of some alcohol blend fuels (E5P5, P5B5 and E5B5) slightly increases than that of light oil at same engine load. This fact indicated that it is possible to control the combustion behaviour in small diesel engine by using the alcohol blend fuels.

Figure 5 shows the $\mathrm{CO}_{2}$ emissions against the engine load as a parameter of fuel properties for alcohol blend fuels. As can be seen from this figure, for all the blend fuels, the $\mathrm{CO}_{2}$ emissions are almost same value of light oil at same engine load. Furthermore, the $\mathrm{CO}_{2}$ emission monotonically increases with increasing the engine load at any fuel type. These facts indicated that the effects of alcohol blend fuels on $\mathrm{CO}_{2}$ emission are not much difference in this study. 


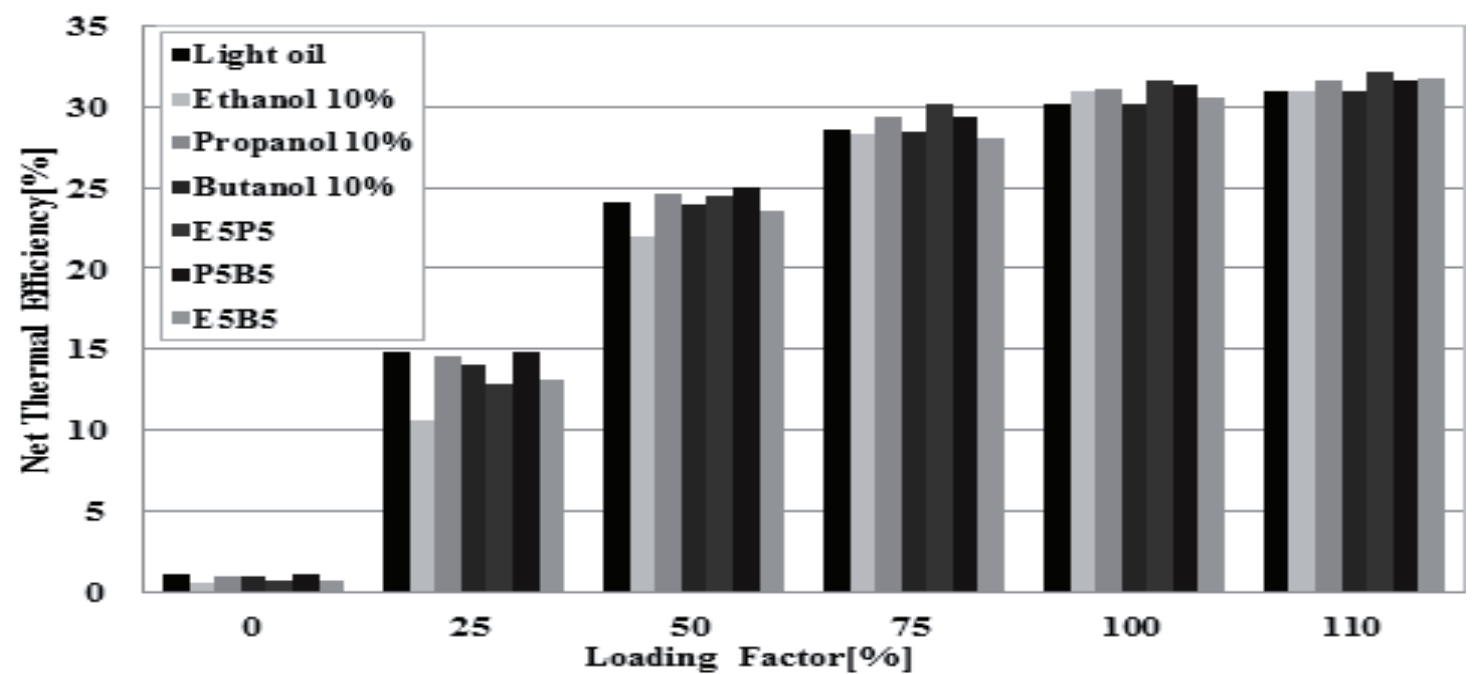

Fig. 4. Net Thermal Efficiency

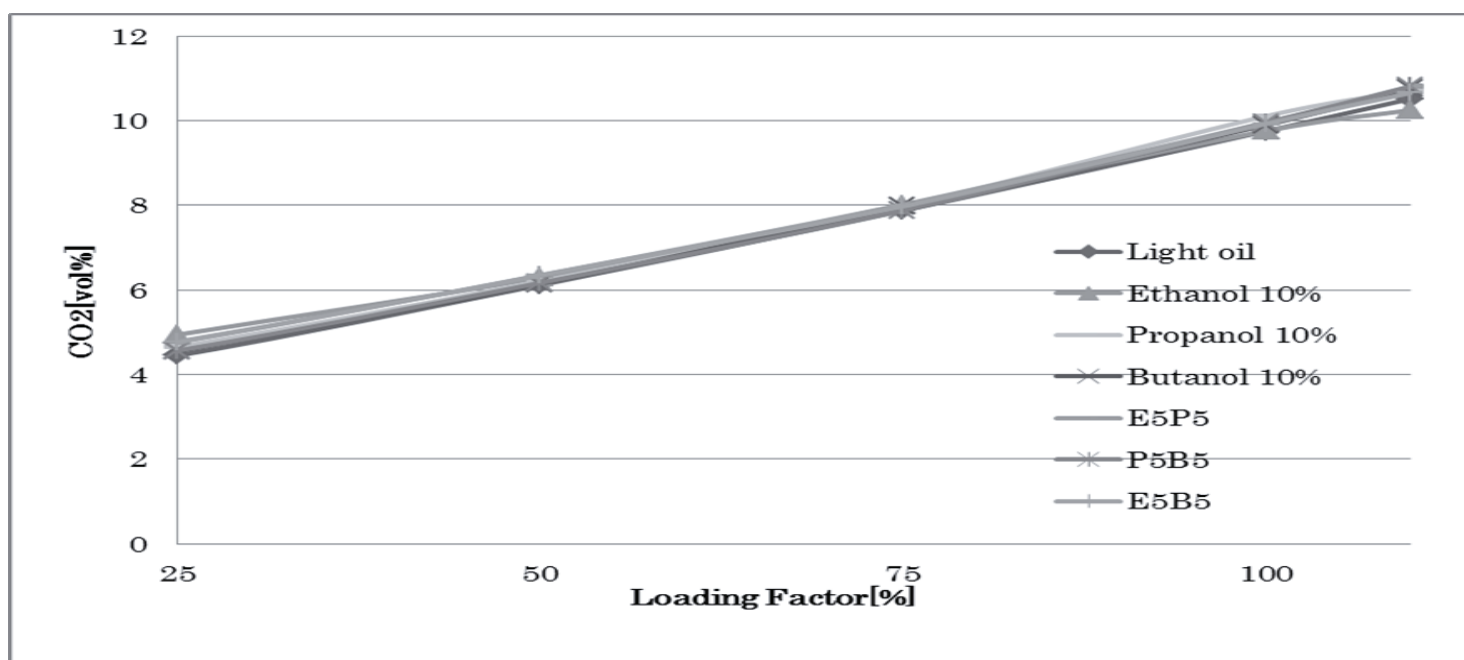

Fig. 5. $\mathrm{CO}_{2}$ emissions

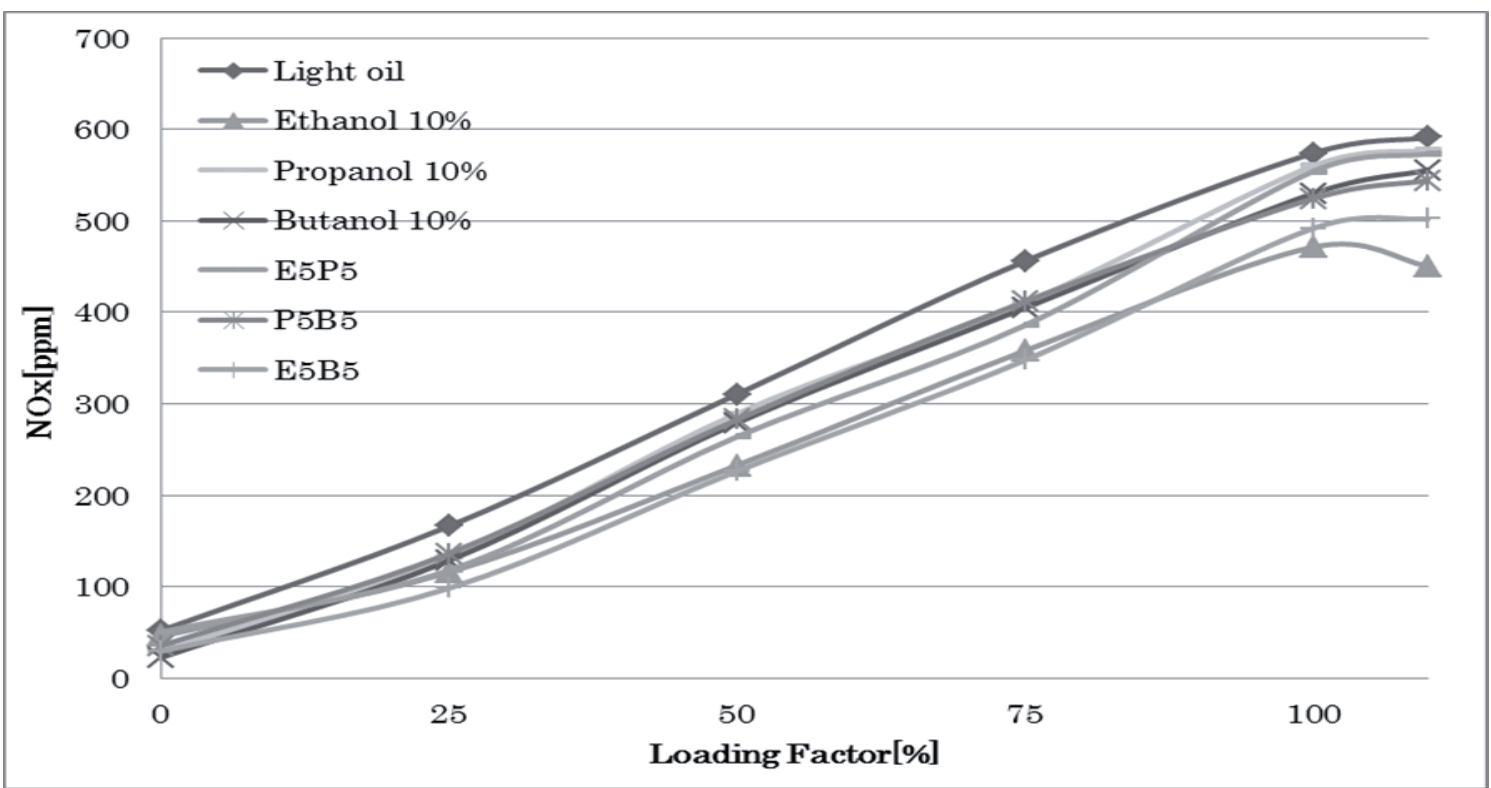

Fig. 6. NOx emissions 


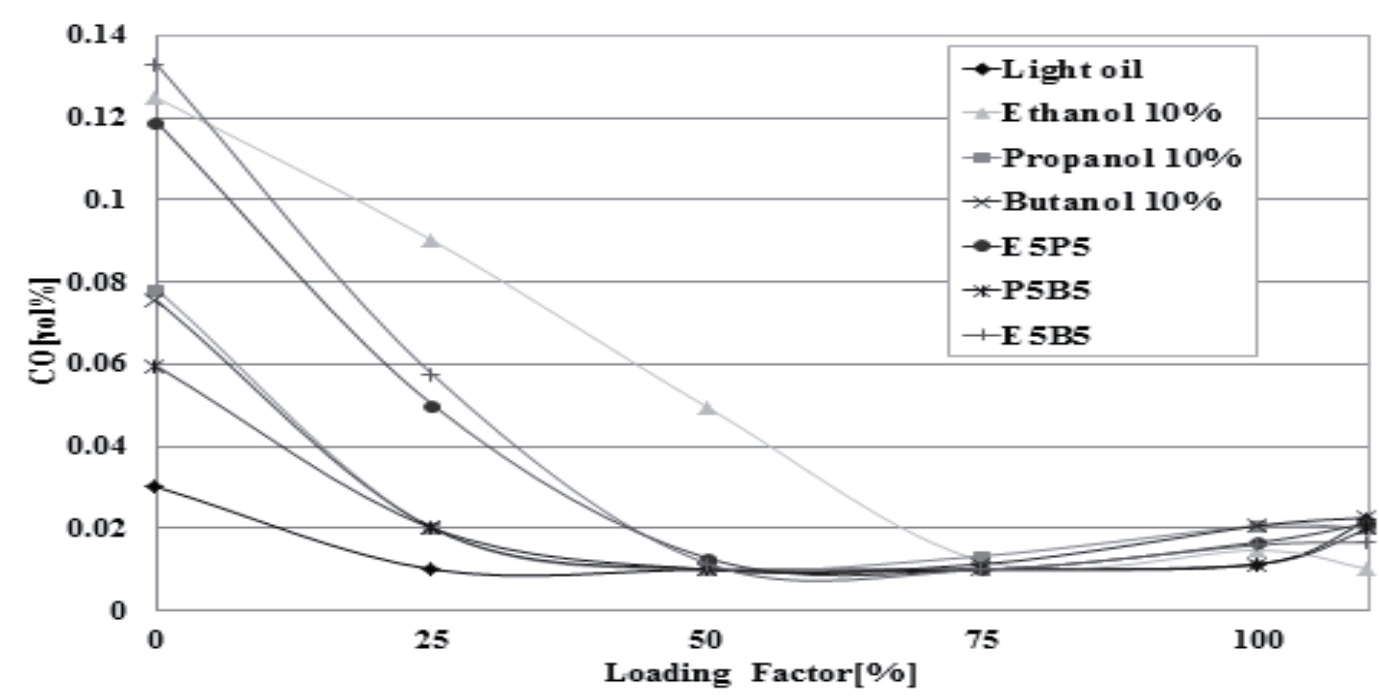

Fig. 7. CO emissions

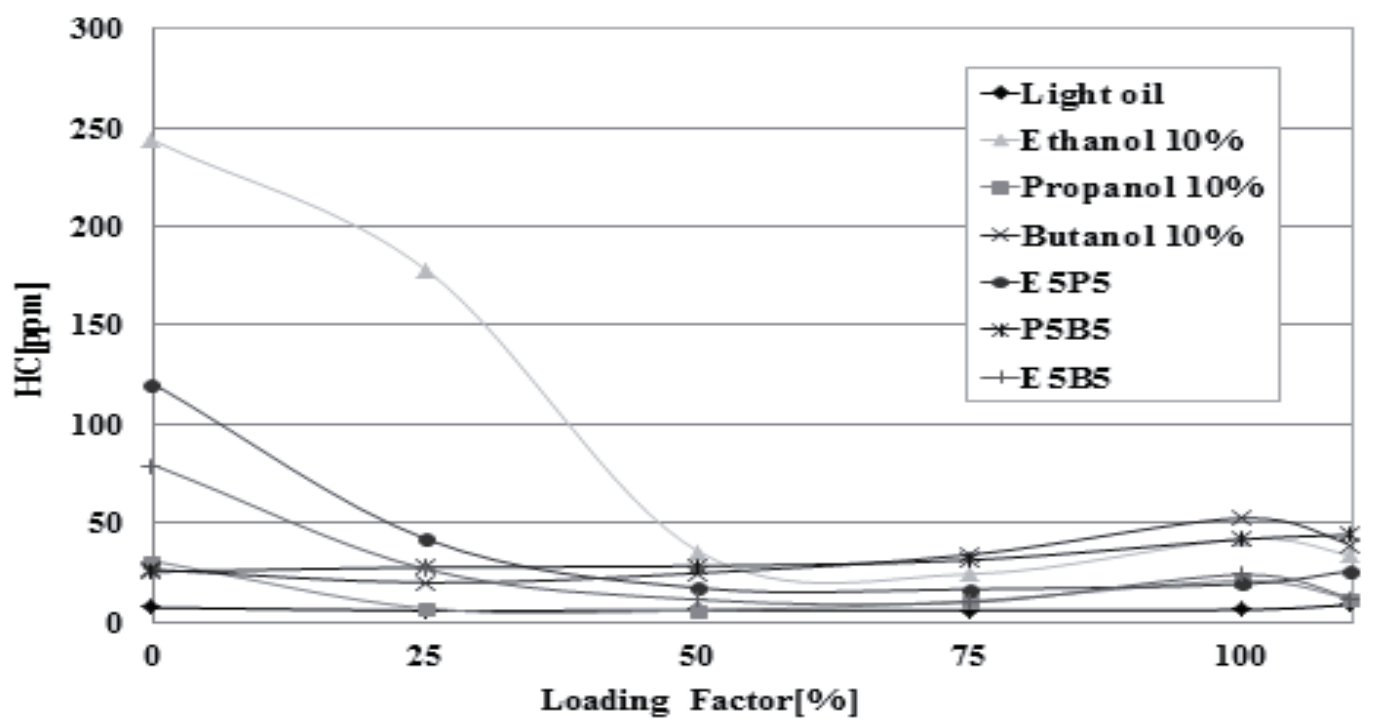

Fig. 8. CO emissions

Figure 6 shows the NOx emissions against the engine load for alcohol blend fuels. As can be seen from this figure, NOx emissions for all the alcohol blend fuels are smaller than that of light oil. It is causes by the decreasing the flame temperature by the addition of alcohol. Furthermore, the reduction ratio increases with increasing the engine load. These results indicated that, the Alcohol blend fuels could possible to reduce the NOx emissions in small diesel engines.

Figure 7 shows the $\mathrm{CO}$ emissions against the engine load as a function of alcohol blend fuel properties. As can be seen from this figure, for all the alcohol blend fuels, the $\mathrm{CO}$ emissions are remarkably bigger than that of light oil under from low to middle engine load without the ethanol $10 \%$. It is causes by the influence of decreasing oxygen of the alcohol blend fuels. Furthermore, the influence of fuel properties on $\mathrm{CO}$ emissions is bigger at low engine load conditions than that of high engine load conditions. This fact indicates that the amount of oxygen in alcohol blend fuels is important role for $\mathrm{CO}$ reduction $[9,10]$.

Figure 8 shows the $\mathrm{HC}$ emissions against the engine load for alcohol blend fuels. From this figure, the $\mathrm{HC}$ emissions for all the alcohol blend fuels are bigger than that of light oil, the effects of alcohol blend properties on $\mathrm{HC}$ emissions are not much difference from middle to high engine load. From these results, it can be seen that, for reducing the $\mathrm{HC}$ emissions by using the alcohol blend fuels, it is necessity to do discuss on the effects of the additional oxygen in the fuels. 


\section{Conclusions}

Experiments have been carried out to examine the influence on combustion characteristics and exhaust emissions for small diesel engine by using alcohol blend fuels. The main conclusions are as follows:

1) It is possible to control the combustion behaviour by using alcohol blend fuels for small diesel engine.

2) The fuel consumption of at any alcohol blend fuels is bigger than that of light oil.

3) The net thermal efficiency of some alcohol blend fuels (E5P5, P5B5 and E5B5) slightly increases than that of light oil.

4) The NOx emissions for all the alcohol blend fuels are smaller than that of light oil.

5) The $\mathrm{CO}$ emissions are remarkably bigger than that of light oil under from low to middle engine load without the ethanol $10 \%$ addition.

\section{References}

[1] Iijima, A., Shoji, H., A study of HCCI combustion characteristics using Spectroscopic Techniques, SAE paper 2007-01-1886, 2007.

[2] Tsutsumi, Y., Hoshina, K., Iijima, A., Shoji, H., Analysis of the combustion characteristics of HCCI Engine operation on DME and Methane, SAE paper No. 2007-32-0041, 2007.

[3] Lim, O. T., et al., The fuel unmixedness effect on DME HCCI combustion using rapid compression and expansion machine, SAE paper No. 2007-42-0042, 2007.

[4] Daisho, Y., et al, Controlling combustion and exhaust emissions in a Direct-injection diesel engine dual-fuelled with natural gas, SAE paper, No. 952436, 1995.

[5] Tomita et al, Effects of EGR and early injection of diesel fuel on combustion characteristics and exhaust emissions in a methane dual fuel engine, SAE paper, No. 2002-01-2723, 2002.

[6] Hill, P. G., et al, $N O_{x}$ reduction from heavy-duty diesel engine with direct injection of natural gas and cooled exhaust gas recirculation, International Journal of Engine Research, Vol. 5, No. 2, pp. 175-191, 2003.

[7] Tomita et al, Combustion characteristics and performance of supercharged micro-pilot natural gas engine, Proceedings of FISITA 2006 World Automotive Congress, Paper No. F2006, p. 230, pp. 1-10, 2006.

[8] Ozaki, J., Iida, N., Effect of Degree of Unmixedness on HCCI Combustion Based on Experiment and Numerical Analysis, SAE paper 2006-32-0046, 2006.

[9] Sugiyama, H., Kawakami, T., Influence of blend fuels on combustion characteristics for small diesel engine, Small Engine Technology Conference SAE of Japan and SAE International, 20076523/2007-32-0023, 2007.

[10] Kawakami, T., Combustion Characteristics for Small Diesel Engine by using Emulsified Blend Fuels of Vegetable Oil and Light Oil, $37^{\text {th }}$ International Scientific Congress on Powertrain and Transport Means EUROPEAN KONES, Vol. 18, No. 4, pp. 185-190, 2011. 